\title{
Slope stability study in open pit and underground mines by means of forensic analysis and radar interferometry
}

\author{
O. Mora Altamira Information, Spain
}

I. Álvarez Universidad de Oviedo, Spain

E. Amor Herrera Hullera Vasco-Leonesa, Spain

\begin{abstract}
This paper demonstrates the capabilities of satellite radar technology to generate complete ground deformation maps of an open pit mine, to follow and detect movement intensities ranging from millimetric to metric scales. Several vulnerable parts of the mine have been studied and monitoring of these very small to very large instabilities has provided valuable information for risk and exploitation management at the mine. A forensic analysis has been also performed and validated with these interferometric radar measurements.

Images from the X-band high resolution images of TerraSAR-X satellite have been acquired between 2008 and 2012 to monitor ground displacement evolution. Two types of ground markers, natural reflectors providing backscattering of the terrain and trihedral artificial reflectors installed on certain areas of the mine have been used. Measurement quality depends on the temporal changes, and several radar Interferometric techniques, including persistent scatterer interferometry (PSI) and Altamira Information developments (stable point network and non-coherent technique) have been used to detect displacement intensities. Phenomena caused by mine activities have been detected, showing a perfect temporal correlation with the mine evolution. The project has also been very useful for the control and analysis of a strong slope instability affecting the open pit, where displacements have been more than $10 \mathrm{~m}$ in some months.
\end{abstract}

\section{Introduction}

Satellite-based radar interferometry (InSAR) is a technique to accurately determine ground surface deformations. The monitoring analysed in this paper is at a coal mine situated in the Leon district of northwestern Spain (Figure 1). It is a large scale openpit excavated in a sequence of alternating lutites, sandstones, and seams of coal. Pit slopes heights range from 100 to $350 \mathrm{~m}$, with individual batters $10 \mathrm{~m}$ in height with 5 to $6 \mathrm{~m}$ wide berms giving an overall slope of $30^{\circ}$. Although now coal is mainly mined by open pit mining operations, previously it was also extracted by underground operations. The low ratios of recuperation by the preceding underground mining allow the present surface mining.

The coal deposit consists of very thick, highly irregular vertical and sub-vertical seams. The Pastora and Competidora seams are the thickest seams in the coalfield, with greatest financial interest, providing all of the coal production for current mining activities. Operations currently focus on the eastern edge of the coalfield.

The area where mining operations are performed on the Competidora seam runs some 1,680 $\mathrm{m}$ in a primarily west-east direction with dips ranging from 60 to $80^{\circ}$. Seam thickness varies from 2 to $25 \mathrm{~m}$, with $14 \mathrm{~m}$ being the most usual thickness. 


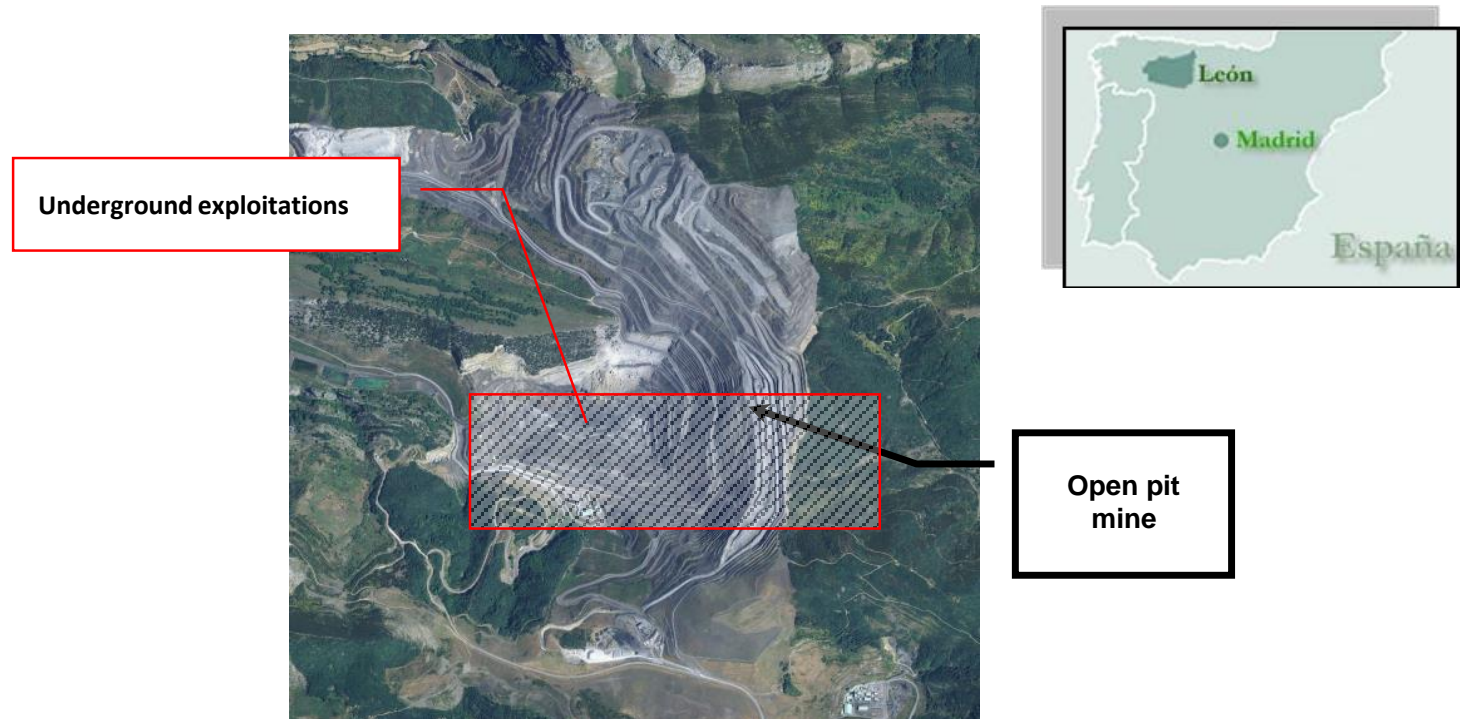

\section{Figure 1 Mine location}

However, the Pastora seam (Santa Lucia Group) runs for 1,600 $\mathrm{m}$ in the same direction, with varying dips, with values close to $30^{\circ}$ in the area of ancient underground exploitation. Its thickness ranges from 7 to $40 \mathrm{~m}$, and within the seam there are lenses (called 'wedges') of varying thicknesses, hardness and composition; ranging from soft slate to hard sandstone.

The coal seams structure is represented in Figure 2 (north-south profile). This figure schematises the disposition of past underground works and the present open pit mine. Note the presence of an important fault.

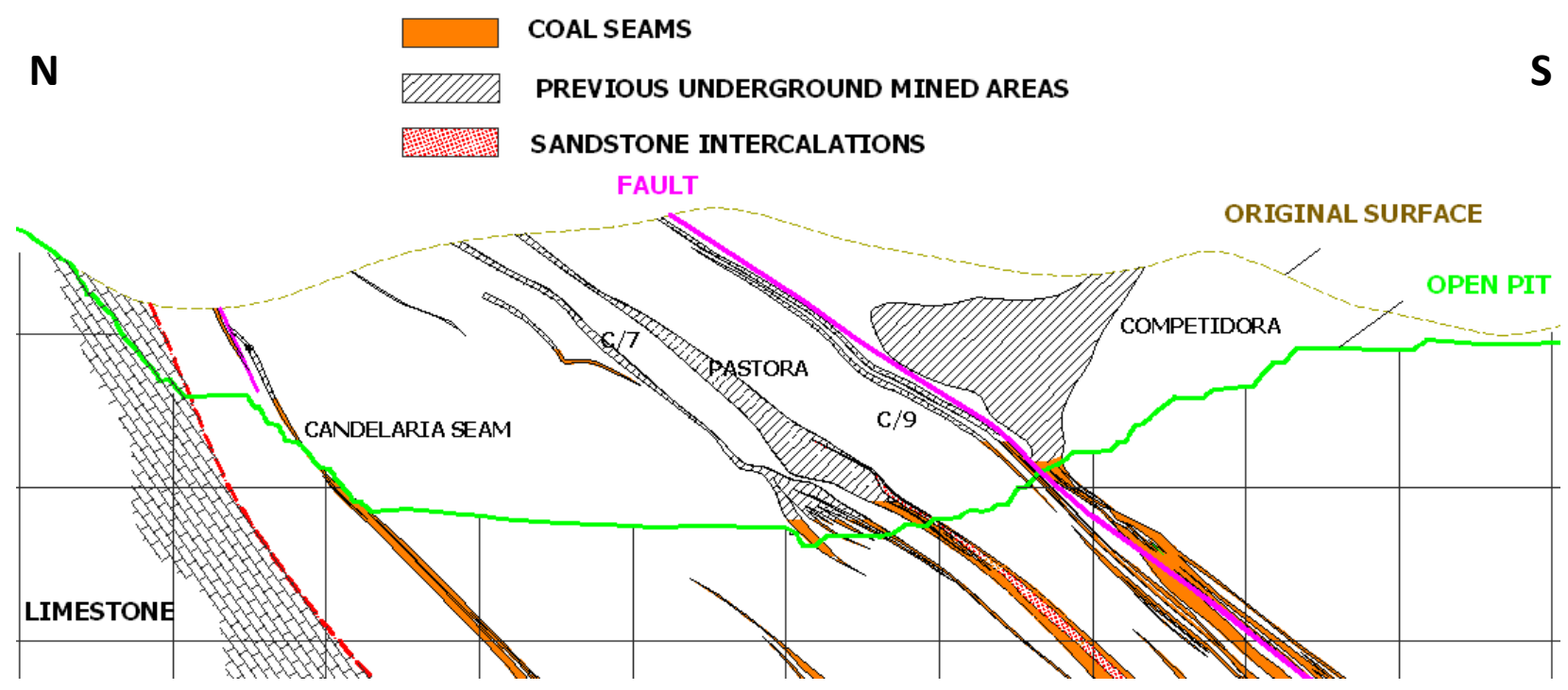

Figure 2 Coal seams, underground and surface works

\section{Description and analysis of the slope stability}

Since 2008, important movements have been observed on the eastern slope, so a geotechnical analysis has been carried out. Mapping of the different material types was performed along different bench levels to determine the lithological characteristics and distribution of the mine's slopes. Each lithology, mainly lutites, sandstones and coal seams, is found in very specific areas in the open pit (Figure 3). 


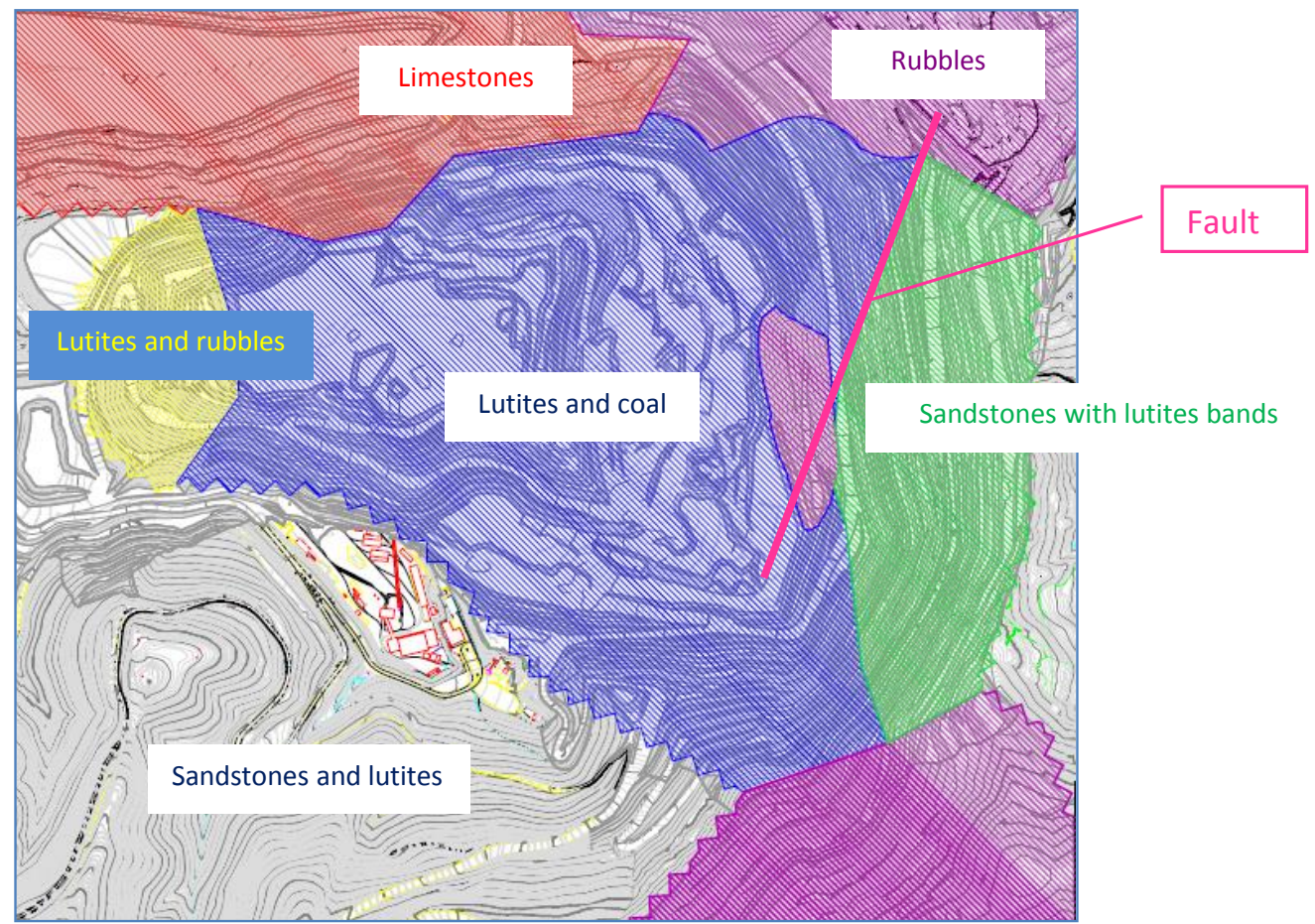

\section{Figure 3 Main lithology}

A study of slope degradation analysed the degree to which the appearance of the slope has been altered, including significant fractures, landslides, and subsidence. To a lesser degree, multiple signs of failure have been detected, indicating fractured layers, dislocated blocks and open discontinuities. All of this evidence has been taken into account to determine rock mass properties. These induced fractures reduce so the block dimension that the natural joint patterns are irrelevant from the point of view of stability. The eastern slope and the south-eastern slope are the most affected areas, with considerable evidence of instability (Figure 4).
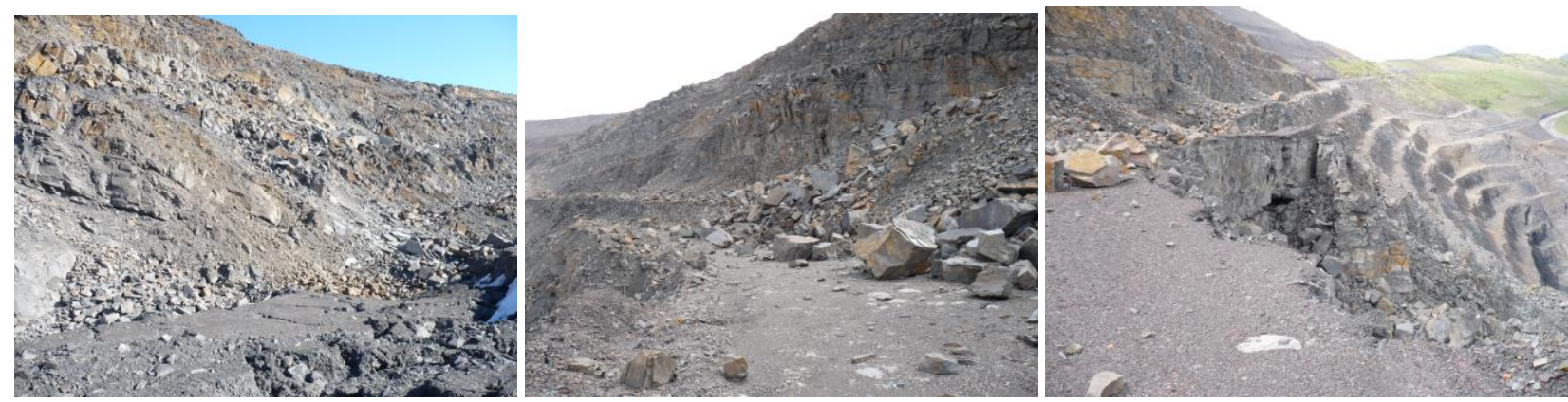

\section{Figure 4 Degradation in an area of the eastern slope}

In addition, along the eastern slope in the Santa Lucía open pit, there is a large fault running close to the Competidora seam, which is mined via underground works. Figure 5 shows the location of the fault area and the movement of the slope. Note that individual batters are $10 \mathrm{~m}$ in height.

Caused by the magnitude of the movements some decisions were taken to:

1. Perform a forensic analysis to evaluate the origin of movements: slope instability, subsidence, water, fault, etc. to adopt the most appropriate stabilisation actions. It is important to remark that before 2008, slope did not present instability signs, only subsidence in the header.

2. Perform a radar satellite control to measure surface deformations. 


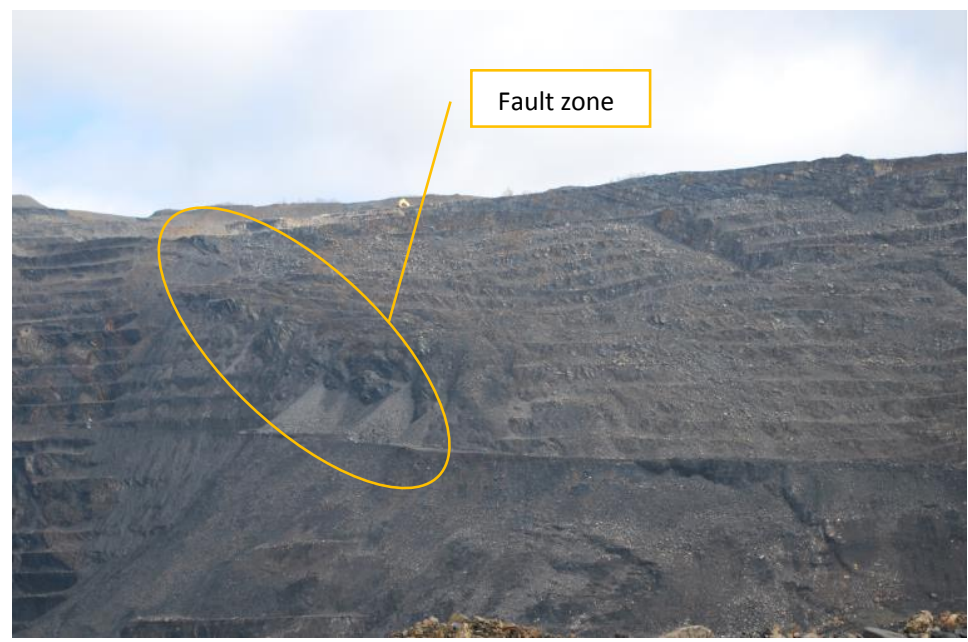

\section{Figure 5 Eastern slope fault area}

It is thought that instability signs are not related with a conventional slope failure (slide) because in the north side of the fault materials have poorer geotechnical properties than in the south side. However, problems are concentrated in the south part.

In order to make this forensic analysis, a two-dimensional numerical model was generated and calculated using the FLAC v6.0 application. This model represents a longitudinal section parallel to the direction of the slope (Figure 6). This model represents the interaction between the underground mining operations and the fault, which is previous to the current slope. The different materials present in the rock mass have been considered in the model, plus their distribution with respect to each other. The presence of the normal fault that crosses the materials has also been taken into consideration. Figure 7 shows the north-south diagram for the analysed model. There are two zones of underground mining: at the north of the fault the most ancient exploitations of Pastora, $\mathrm{C} / 9$ and $\mathrm{C} / 7$ seams and at the south of the fault most recent exploitations of Competidora seam.

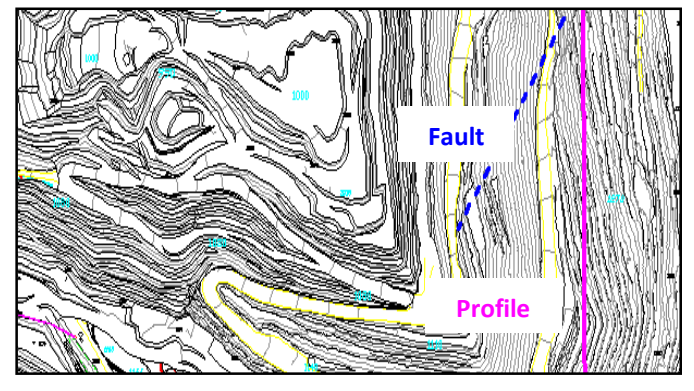

Figure 6 Outline of the profile used for the model and the fault location

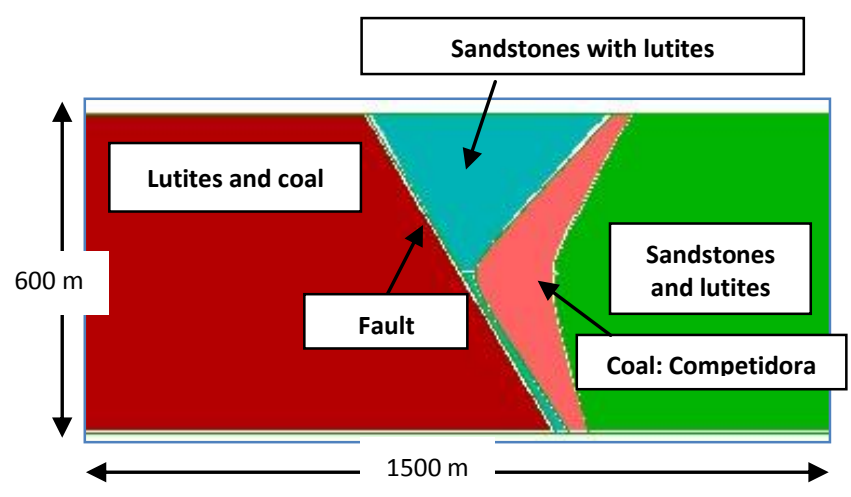

Figure 7 Model diagram

The model has been divided into several calculation phases to simulate, as closely as possible, the operations that are performed. A total of eight phases have been defined:

- Phase 1: Initial stress in the rock mass without any part of the rock mass being subject to underground (and subsequently open pit) mining operations.

- Phases 2, 3 and 4: Successive mining of three small coal seams located at different levels in an area located to the north of the fault.

- Phases 5, 6, 7 and 8: Sublevel caving of four different levels in the Competidora seam, with a $30 \mathrm{~m}$ high vault support structure and leaving intermediate $70 \mathrm{~m}$ rock masses. The last exploitation 
levels (phases 7 and 8 ) are concurrent with the development of the open pit excavation, when the eastern slope reaches about $300 \mathrm{~m}$ height and the fault is 'liberated' along more than $350 \mathrm{~m}$. Between phase 7 and 8 began the radar monitoring. Phase 7 began during 2008 and phase 8 finished in 2010.

Interferometric radar monitoring begins during phase 7 (sublevel caving). This phase of sublevel caving was located directly in the fold hinge of the Competidora seam, in the area of the seam closest to the fault, at a depth of $375 \mathrm{~m}$ (Figure 8). The maximum displacements are located in the ceiling of the area where sublevel caving operations took place, with values greater than $30 \mathrm{~m}$ for vertical movements and $5 \mathrm{~m}$ for horizontal displacements. This phase, located very close to the fault zone, causes significant subsidence in the south section of the fault area, as can be seen by the value of $10 \mathrm{~m}$ recorded at control point 2 (Figure 9). During this phase, the slope began with the instability signs and, as commented before, radar monitoring initiates. It is in this moment when the geometry of slope interacting with the fault allows a new movement towards the opening sliding trough this discontinuity.

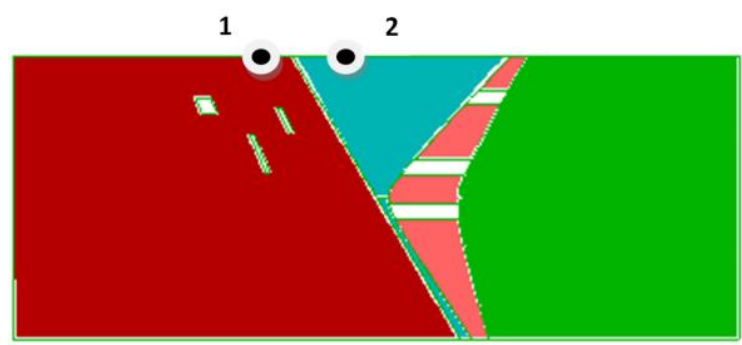

Figure 8 Numerical model phase diagram. Location of control points (1 and 2)

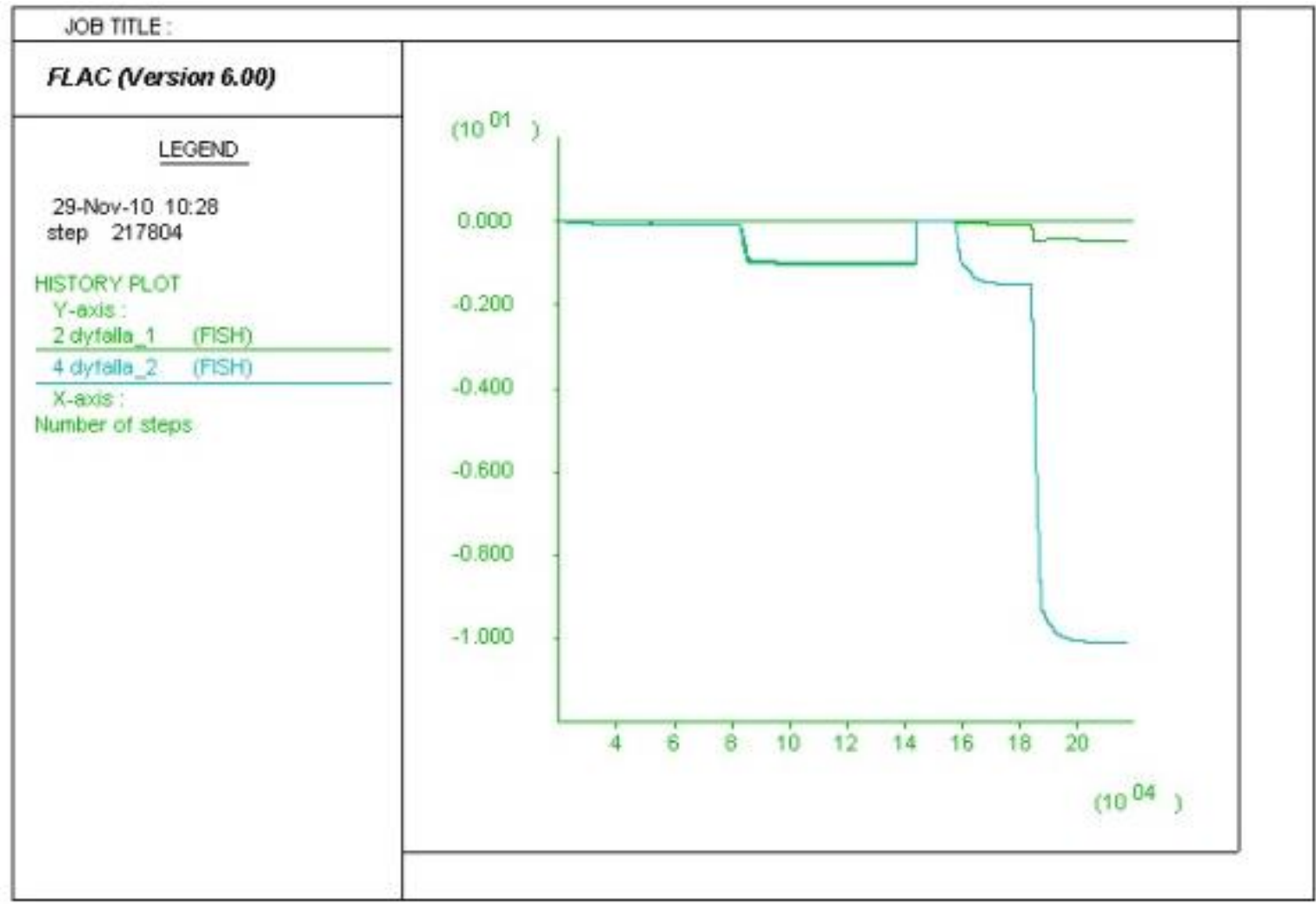

Figure 9 Evolution of vertical displacements at the control points during phase 7

The last study phase (phase 8) consisted in the simulation of sublevel caving of the Competidora seam below the fault fold hinge, at a depth of $475 \mathrm{~m}$. With the plasticity obtained we can see how plastification now affects all of the seam and the surrounding area. The most important damage, due to cutting forces, is found near to the surface, in the area located to the right of the fault (Figure 10). 


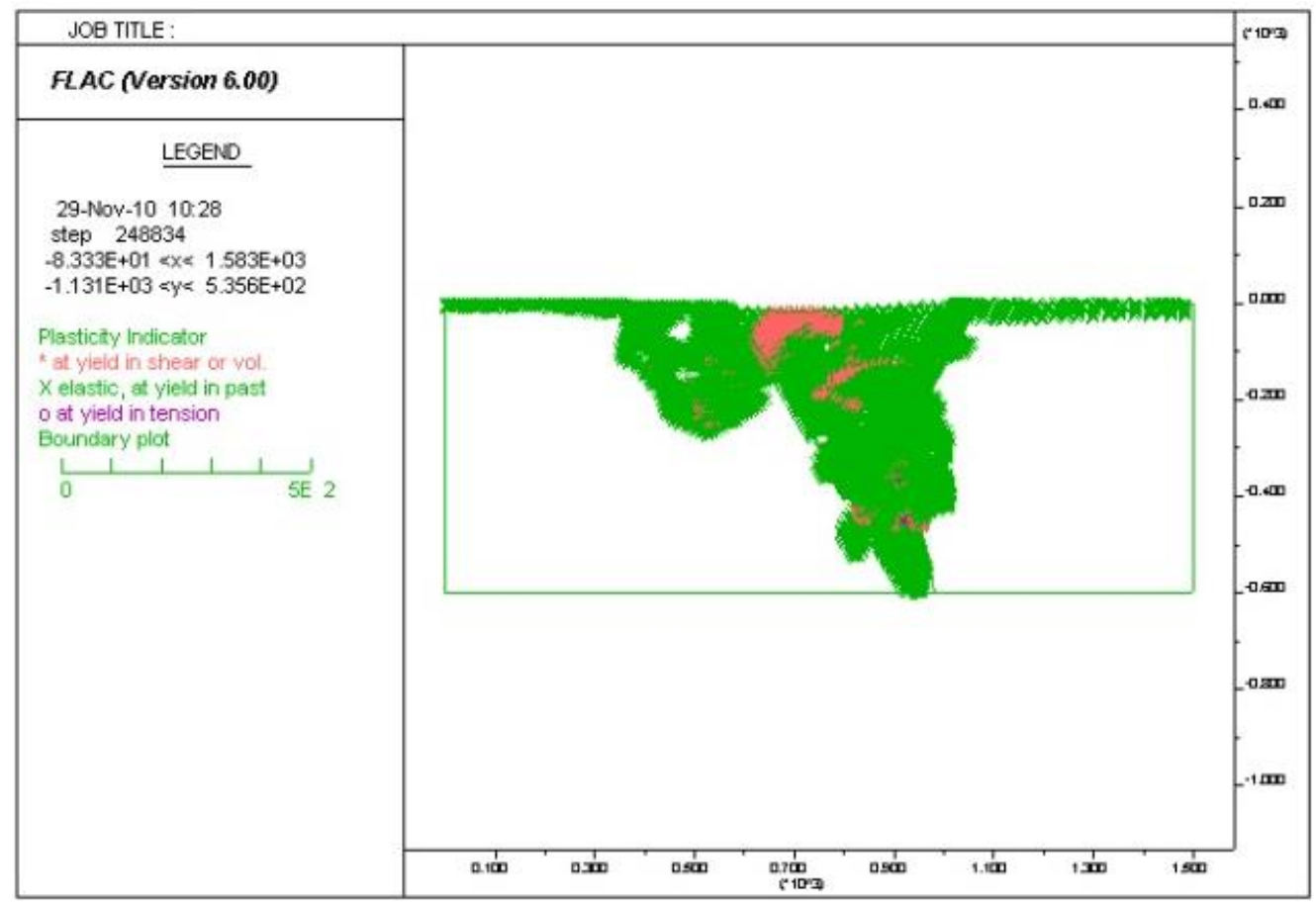

Figure $10 \quad$ Plasticity in phase 8

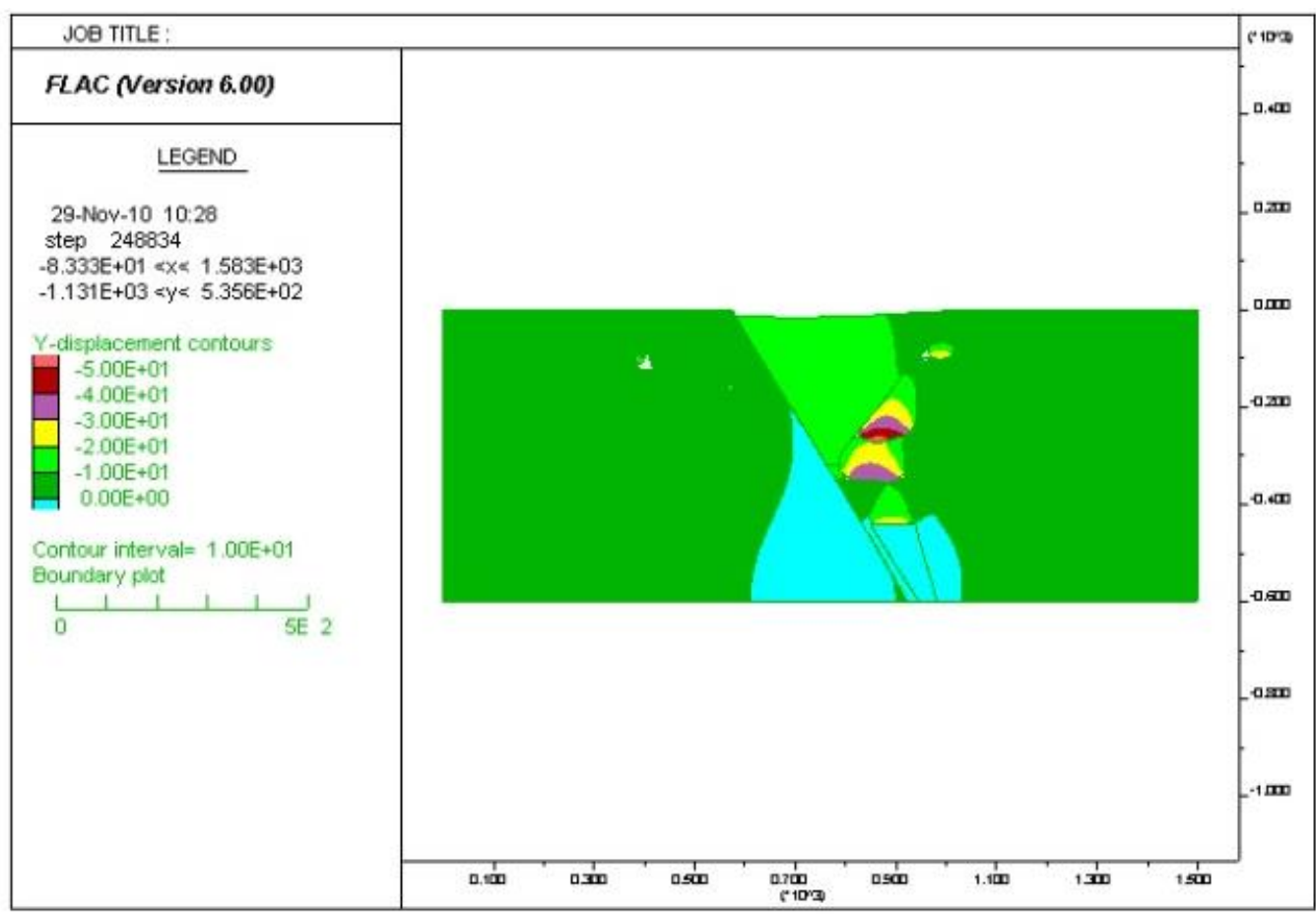

Figure 11 Vertical displacements in phase 8

On the other hand, the movement trend witnessed in this phase is practically identical to that seen in the previous sublevel caving phases. Horizontal movement values are close to $5 \mathrm{~m}$, whilst vertical displacements reach values of $30 \mathrm{~m}$ in the ceiling. Displacements of $50 \mathrm{~m}$ were registered in the areas that had been subject to sublevel caving in previous phases (Figure 11). This is due, logically, to the continuous strain to which the materials in previously mined areas continue to be subjected.

The increase in subsidence at control point 2 recorded in this phase was $3 \mathrm{~m}$ in comparison to the previous phase, giving a value of $13 \mathrm{~m}$. The movement at point 1 continues to be extremely reduced $(15 \mathrm{~cm})$. 
Viewing the model results, the principal movements in the slope are caused by the interaction between fault and underground mining of lower levels of Competidora seam, so there are two differential zones in both sides of the fault: in the south part with metric movements (subsidence and displacements sliding trough the fault) and in the north with milimetric or centimetric movements (caused only by subsidence). As shown in following sections, interferometric radar control confirms this hypothesis.

In this model, is not considered that, when the slope is excavated there is a new possibility of movement (not only vertical) on those altered materials approaching the fault: towards the opening, with an important horizontal component.

\section{Radar data used}

Images from the German earth resources satellite TerraSAR-X have been acquired over the mine area during the last four years. These images have been acquired in the stripmap mode, which gives an approximate spatial resolution of $3 \mathrm{~m}$ on ground. Table 1 shows the list of all the SAR acquisitions divided into different colours that correspond to each yearly study, beginning in 2008-2009 and ending in 2012. It is important to note that images are not acquired during the winter period, when snow coverage degrades the signal quality backscattered to the satellite. In this paper, results are focused on the last two years of the study (2011 and 2012).

The area under specific study is the east slope of the open pit mine, and Figure 12 compares an orthophoto of the study area with the SAR image obtained from combining eight acquisitions in 2012. It is important to note the different bright levels that correspond to different backscattering intensity depending on the surface characteristics. As derived from the previous forensic analysis, the study area is affected by medium (millimetric-centimetric) and strong (metric) displacements.

Table 1 List of SAR images (TerraSAR-X satellite) during the last four years

\begin{tabular}{ccccccccc}
\hline \multicolumn{7}{c}{ TerraSAR-X Acquisitions } \\
\multicolumn{7}{c}{ Descending Orbit } \\
\hline$\#$ & Date & Orbit & $\#$ & Date & Orbit & $\#$ & Date & Orbit \\
\hline 1 & $27 / 10 / 2008$ & 7791 & 15 & $18 / 11 / 2009$ & 13469 & 29 & $07 / 08 / 2011$ & 22988 \\
2 & $07 / 11 / 2008$ & 7958 & 16 & $14 / 02 / 2010$ & 14805 & 30 & $09 / 09 / 2011$ & 23489 \\
3 & $29 / 11 / 2008$ & 8292 & 17 & $08 / 03 / 2010$ & 15139 & 31 & $12 / 10 / 2011$ & 23990 \\
4 & $21 / 12 / 2008$ & 8626 & 18 & $10 / 04 / 2010$ & 15640 & 32 & $14 / 11 / 2011$ & 24491 \\
5 & $01 / 01 / 2009$ & 8793 & 19 & $13 / 05 / 2010$ & 16141 & 33 & $17 / 12 / 2011$ & 24992 \\
6 & $03 / 02 / 2009$ & 9294 & 20 & $15 / 06 / 2010$ & 16642 & 34 & $27 / 04 / 2012$ & 26996 \\
7 & $25 / 02 / 2009$ & 9628 & 21 & $18 / 07 / 2010$ & 17143 & 35 & $10 / 06 / 2012$ & 27664 \\
8 & $23 / 04 / 2009$ & 10296 & 22 & $31 / 08 / 2010$ & 17811 & 36 & $02 / 07 / 2012$ & 27998 \\
9 & $26 / 05 / 2009$ & 10797 & 23 & $11 / 09 / 2010$ & 17978 & 37 & $04 / 08 / 2012$ & 28499 \\
10 & $17 / 06 / 2009$ & 11131 & 24 & $25 / 10 / 2010$ & 18646 & 38 & $06 / 09 / 2012$ & 29000 \\
11 & $20 / 07 / 2009$ & 11632 & 25 & $27 / 11 / 2010$ & 19147 & 39 & $09 / 10 / 2012$ & 29501 \\
12 & $11 / 08 / 2009$ & 11966 & 26 & $30 / 04 / 2011$ & 21485 & 40 & $11 / 11 / 2012$ & 30002 \\
13 & $24 / 09 / 2009$ & 12634 & 27 & $02 / 06 / 2011$ & 21986 & 41 & $14 / 12 / 2012$ & 30503 \\
14 & $16 / 10 / 2009$ & 12968 & 28 & $05 / 07 / 2011$ & 22487 & & & \\
\hline
\end{tabular}



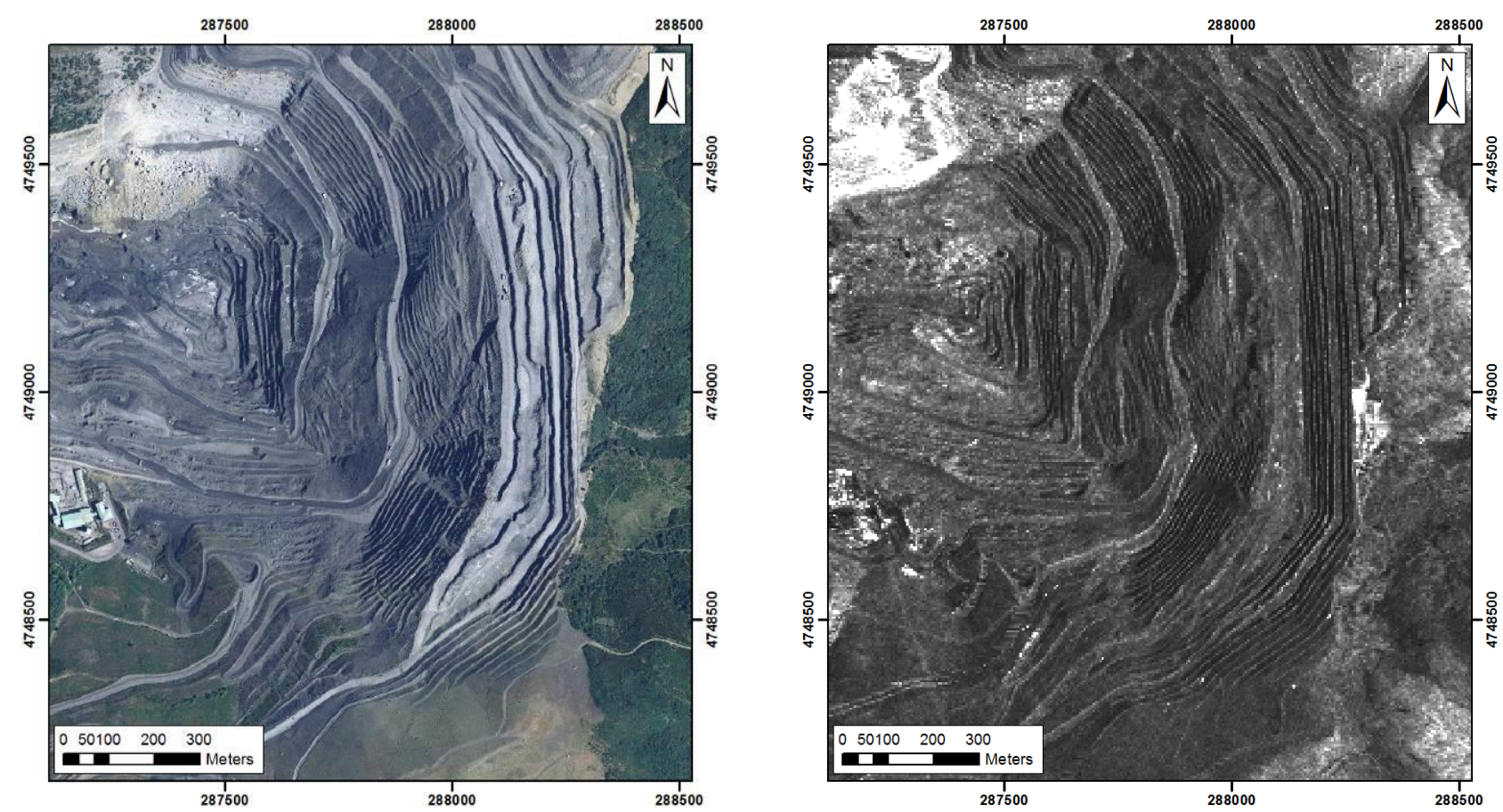

\section{Figure 12 Orthophoto (left) and multi-mean SAR image (right) generated with data acquired during 2012}

\section{$4 \quad$ Radar methodologies}

As presented before, displacements affecting mine slopes can range from some millimetres to several meters. These different behaviors need to be studied using different processing techniques on SAR data. A first classification can be done based on displacement intensity:

- Millimetric and centimetric movements: These events can be measured using PSI techniques (Adam et al., 2009), like the stable point network (SPN) methodology developed by Altamira Information (Arnaud et al., 2003). This technique uses the phase information from the radar signal in order to precisely detect the ground motion. Millimetric precision is obtained with SPN, and a maximum threshold of ground velocity can be measured depending on the number of SAR images and the temporal period of the study. Typically, this maximum velocity ranges from 15 to $30 \mathrm{~cm} /$ year in case of X-band satellites, like TerraSAR-X.

- Metric movements: Due to the limitations of PSI techniques regarding the maximum measurable velocity, Altamira Information developed another methodology, non-coherent technique (NCT), to detect metric displacements for the mining industry. These sometimes fast movements can represent a major problem for the mine safety, mainly in infrastructure and working areas.

A combination of both methodologies is presented in this paper, obtaining a complete displacement map of the area of interest, no matter the movement intensity. Two different types of measurement points have been used for the monitoring, classified as natural and artificial reflectors:

- Natural reflectors: These are the measurable points of the surface under study. They must not change their surface characteristics during the temporal period of monitoring. These natural reflectors can be buildings, infrastructures, bare soils, low-vegetation areas, etc. Not all the points in the image can be classified as natural reflectors, and therefore only a part of the image pixels can be measured by means of radar interferometry.

- Artificial reflectors: Trihedral structures that can be installed on surface, in order to ensure measurable points where natural reflector density is very low. Artificial reflectors do not need any 
additional maintenance, and power supply is not required. Figure 13 shows an example of natural points and artificial reflectors.
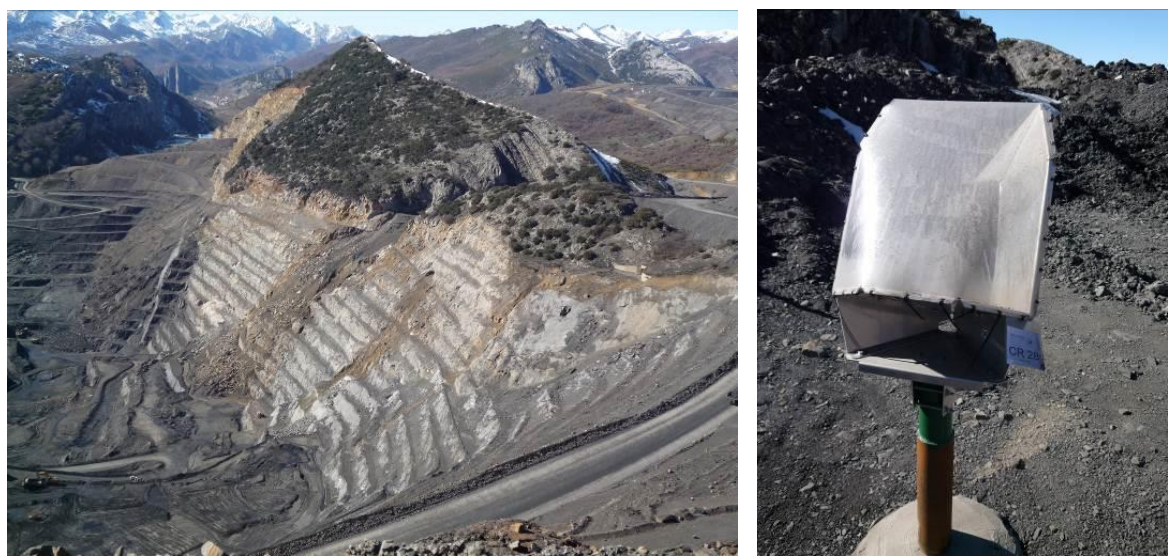

Figure 13 Natural (left) and artificial reflectors (right) installed in the mine slope

\section{$5 \quad$ Radar results}

The two different radar techniques used for the monitoring of slope stability (SPN and NCT), have the objective of detecting several scales of ground movement, from millimetric to metric. This is a very important point, since movements found in a mining area can present different behaviours with diverse displacement intensity. Obtained results on the eastern slope of the mine are presented in the following sections.

\subsection{Stable point network (SPN)}

This methodology allows detecting millimetric and centimetric displacements with high accuracy. This advanced interferometric technique uses a stack of SAR images (typically 15-30) to measure ground deformations with millimetric precision (Duro et al., 2003). During the processing, the ground scatterers not affected by temporal decorrelation are identified; these are called persistent scatterers or stable points. They are natural objects over the ground surface that provide a very good reflection to the satellite throughout the entire stack of images. These points present a reduced level of noise, which allows very reliable measurements. Furthermore, the atmospheric effects are estimated and compensated during the processing to derive highly accurate elevation and displacement values for each stable point. The highly precise error compensation generates time series charts that provide a visualisation of the evolution of the displacement of each stable point.

Figure 14 shows displacement maps for two different years (non-winter months), 2011 and 2012. Differences on ground deformation can be observed, mainly in the southern part of the slope, where velocity is much lower during 2012. Another important issue is the distribution of measurement points, depending on surface changes in the open pit. For example, there are fewer points present during 2011, when a higher surface activity was reported.

A large area without detected points is clearly visible for both years in the centre of the slope. This is due to extreme displacements, more than $5 \mathrm{~m}$, and for which results are presented in the next section. These displacements cannot be measured by means of interferometric phase due to aliasing (extreme velocity).

Ground deformation maps of Figure 14 correspond to natural reflectors measurements. Nevertheless, additional information can be retrieved using artificial reflectors, as shown in Figure 15. In this case, six aluminium trihedral reflectors have been installed covering the studied slope from north to south. The three northern reflectors are located in a stable zone, with the other three installed on a deformation area. Time series analyses for the points confirm the same movement pattern obtained from natural reflectors. This confirms the functionality of both approaches (i.e. natural and artificial reflectors). The advantage of artificial points is that only three or four SAR images are necessary for a first processing, no matter the 
season (winter or summer), while a larger dataset (typically more than 15 acquisitions) is recommended for SPN on natural reflectors.
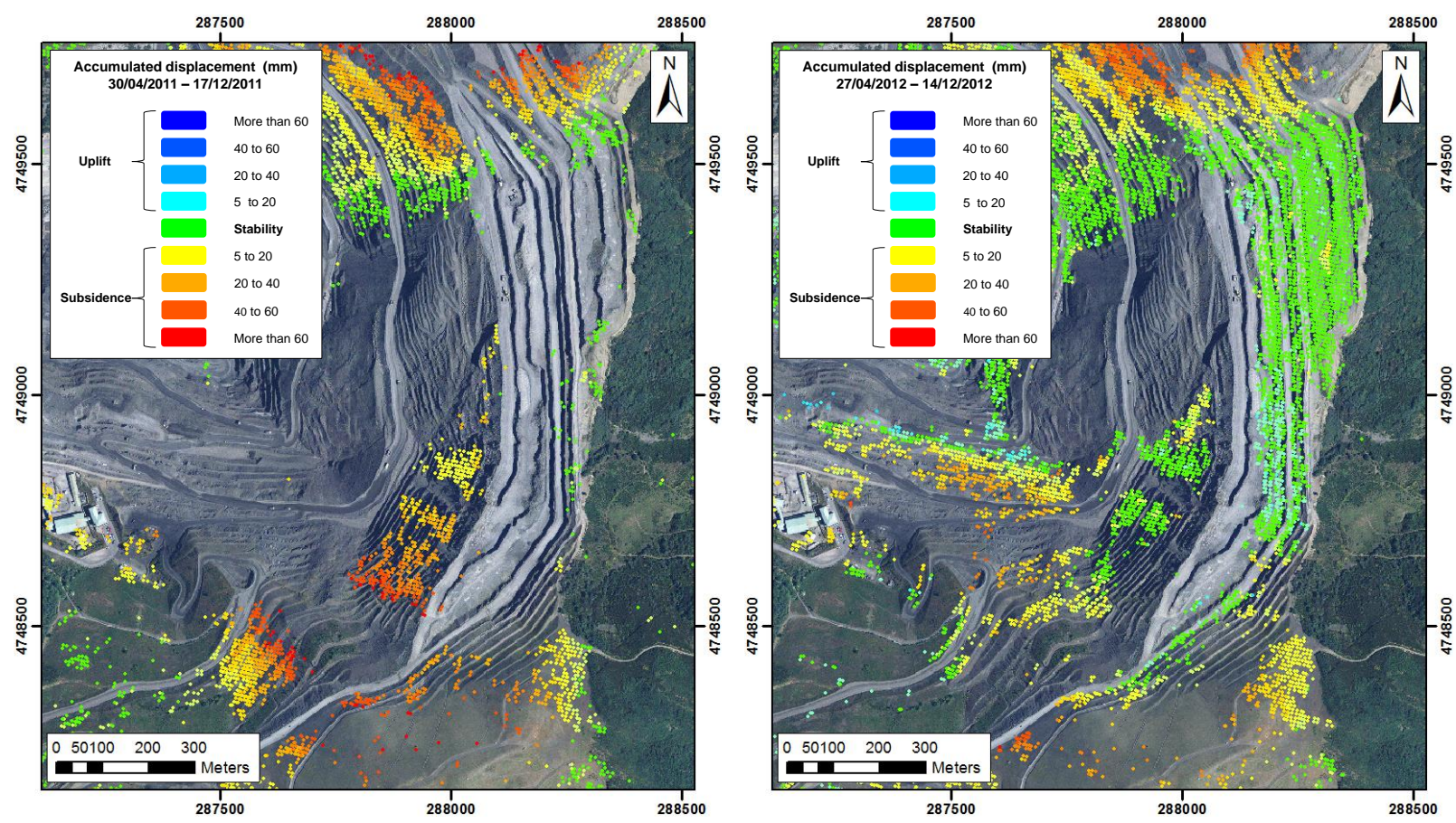

Figure 14 Slope ground displacement map from SPN technique for two different years, 2011 (left) and 2012 (right)

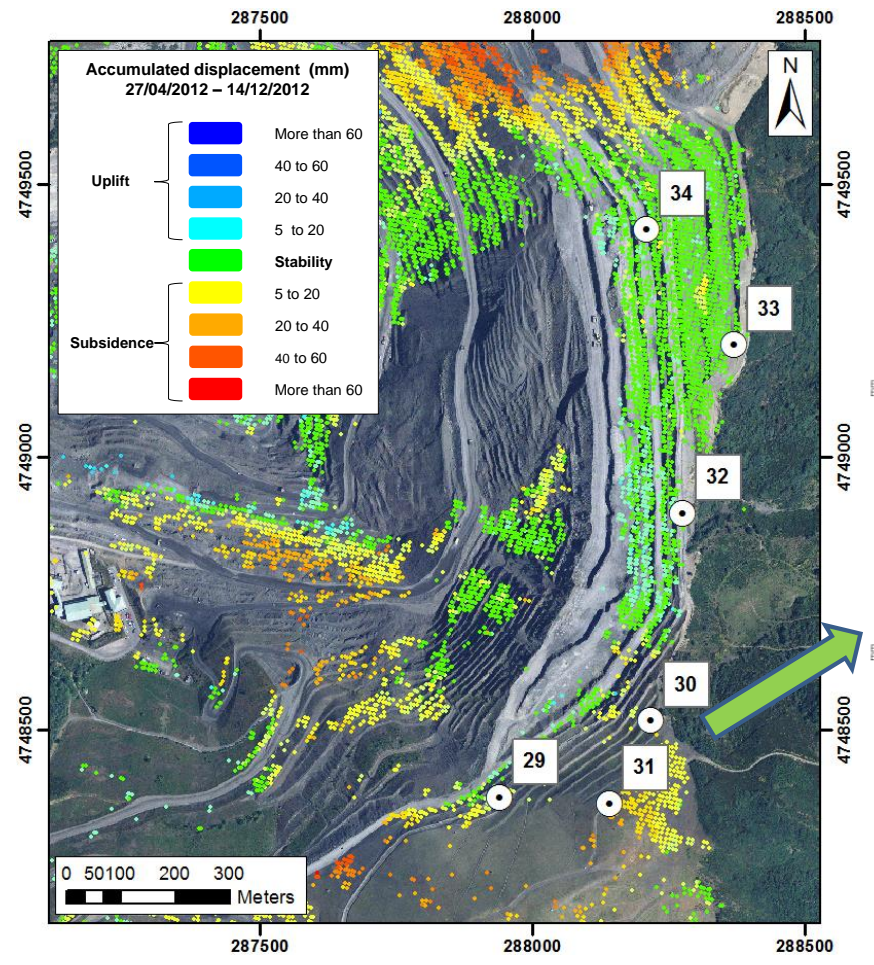

Deformation time series

Figure 15 Ground displacement time series $(\mathrm{mm})$ for artificial reflectors installed in
the slope area

\subsection{Non-coherent technique (NCT)}

This technique has been developed to monitor large ground displacements, in the order of meters. It is necessary in order to measure those movements larger than the maximum value for the SPN methodology, 
which depending on the number of SAR images and the temporal span can be about $20-30 \mathrm{~cm} /$ year. Results of the NCT processing are presented in Figure 16, where the strong intensity (more than $5 \mathrm{~m}$ ) and affected area are clearly visible. Again the displacements in 2012 are lower compared with 2011.

In order to show the complementary nature of the two techniques, Figure 17 shows the combination of the SPN and NCT maps. Note that the location of SPN natural reflectors is restricted to milimetric-centimetric displacements, while the NCT map is restricted to the metric movements; generating together a complete deformation map of the area of interest.
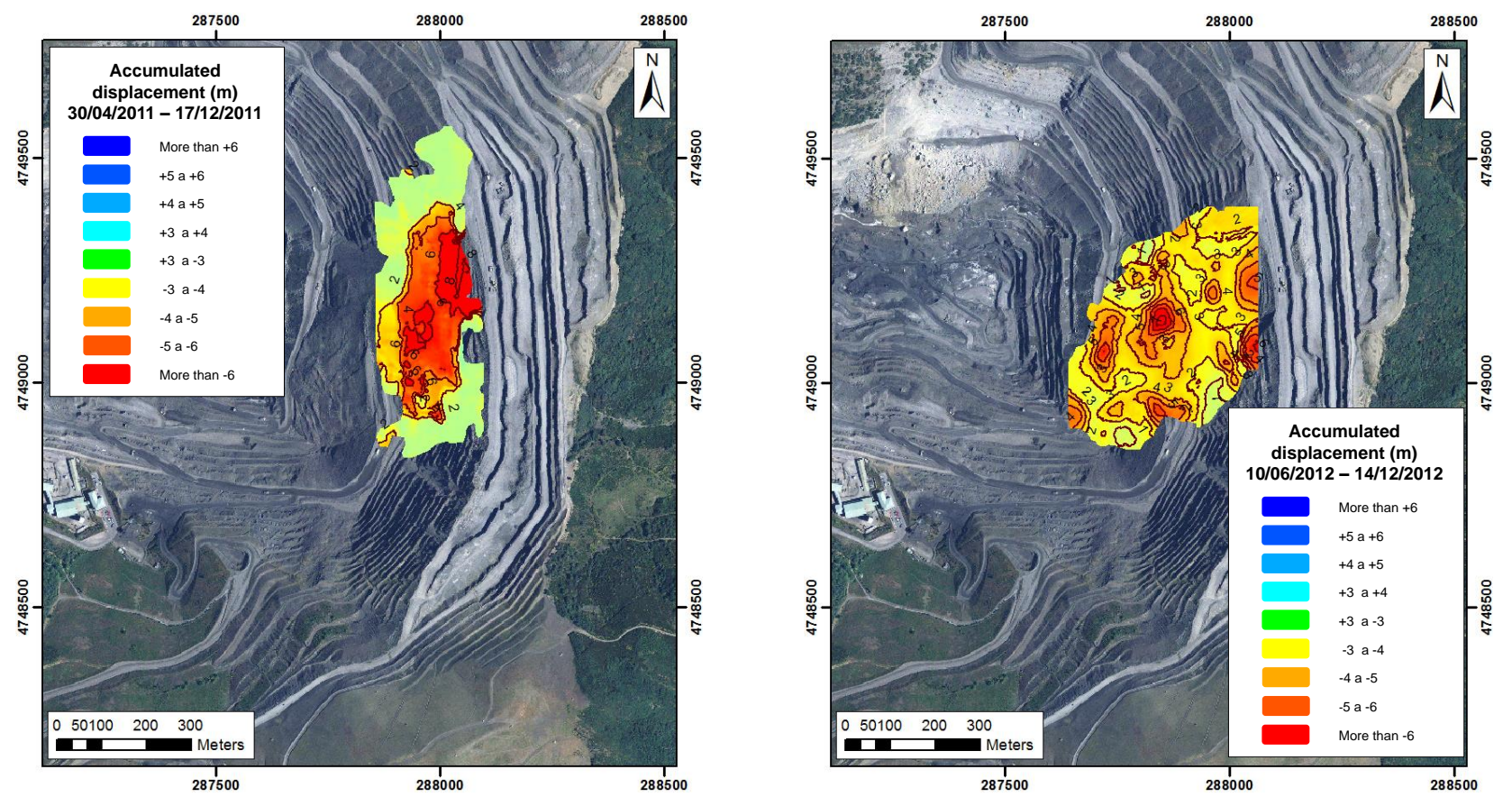

Figure 16 Slope ground displacement map from NCT technique for two different years, 2011 (left) and 2012 (right)
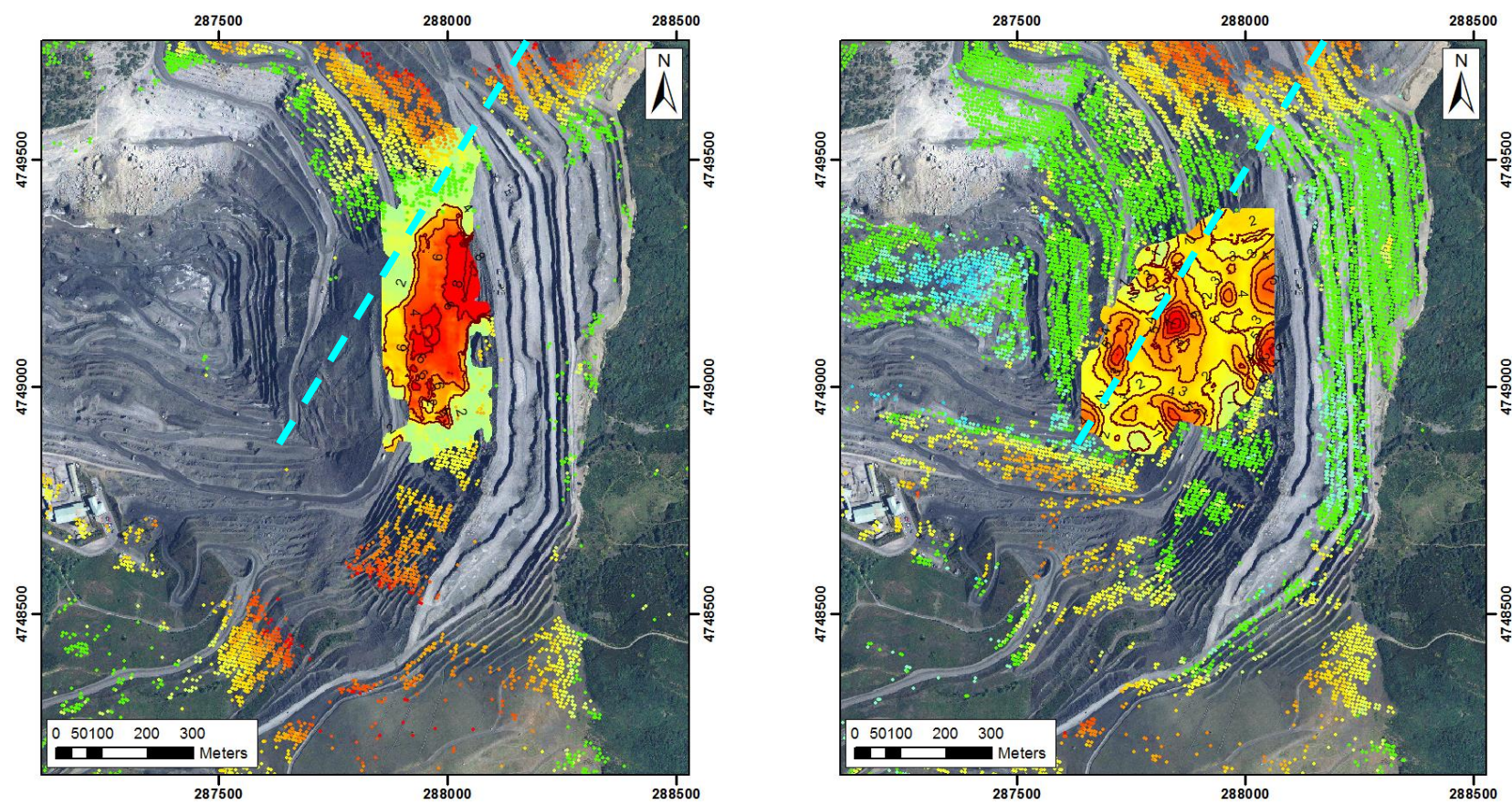

Figure 17 Combined (SPN and NCT) slope ground displacement map for two different years: 2011 (left) and 2012 (right), with the same legends from Figures 4 and 6. Fault location is presented with a dashed line 
These results are consistent with those obtained with forensic analysis taking into account both parameters:

1. Magnitude of movements: Presence of metric and centimetric displacements. Movements about $6 \mathrm{~m} \mathrm{(2011)} \mathrm{in} \mathrm{the} \mathrm{south} \mathrm{of} \mathrm{the} \mathrm{fault} \mathrm{corresponding} \mathrm{with} \mathrm{the} \mathrm{end} \mathrm{of} \mathrm{phase} 7$ and most important subsidence of phase 8 in the model, and the movements of 2012 corresponding with the final subsidence of phase 8 and the displacement of the slope trough the fault (Figure 17).

2. Location of movements: All metric displacements are located in the same side of the fault, and the minor movements (milimetric or centimetric) in the other side.

Moreover, radar satellite control has allowed establishing a correlation between time and subsidence, since after the end of exploitation in 2010 important movements are still observed during one year. Nevertheless, these movements are drastically reduced in magnitude after two years. Taking into account their geometry they are caused by the slope's superficial alteration, since materials are highly altered and displacement's direction goes to the open pit hole following fault's orientation.

\section{Conclusions}

The application of advanced satellite interferometric techniques proves to be a good tool to quantify and map slope instabilities. The combination of radar interferometry with forensic analysis allows confirming the suitability of different models in order to understand the behaviour of ground instabilities in mining environments. InSAR measurements provide support in the evaluation of the existing subsidence mechanisms and are effective risk management tools used in worldwide mines to activate mitigation measures when required.

This paper shows an approach to understand and interpret the measured InSAR motions in both open pit and underground mines by using natural and artificial reflectors and by applying SPN and NCT technologies. The ranges of measurement are necessary to cover the range of movements detected and provide a comprehensive approach.

The discussed results demonstrate the suitability and the potentiality of InSAR technology to complement and under certain conditions even supplement other in situ surveying techniques for a better characterisation and understanding of the mine induced ground deformations.

Advanced InSAR processing techniques for mining demonstrate several distinctive parameters that define this remote sensing methodology, the most important ones being:

- High density of measurements points that allows to precisely set the boundaries of the ground deformation and to map the different shapes and magnitudes affecting each zone (thousands of points in $\mathrm{km}^{2}$ ).

- High precision of measurements (1 to $2 \mathrm{~mm}$ ). Pixel size ( $3 \mathrm{~m}$ ) allowing an sampling of the results.

For the mining operator, the use of these techniques, together with the application of geotechnical knowledge provided by the University of Oviedo is enabling to better understand the behaviour of terrain which is simultaneously affected by underground and external excavations.

\section{Acknowledgement}

Emilio Amor of Hullera Vasca Leonesa (HVL) assisted in the preparation of plots in this paper and provided editorial assistance on this paper; his generous assistance is gratefully acknowledged.

\section{References}

Adam, N., Parizzi, A. and Crosetto, M. (2009) Practical Persistent Scatterer Processing Validation in the Course of the Terrafirma Project, Journal of Applied Geophysics, Vol. 69, pp. 59-65. 
Arnaud, A., Adam, N., Hanssen, R., Inglada, J., Duro, J., Closa, J. and Einederm, M. (2003) ASAR ERS interferometric phase continuity, in Proceedings International Geoscience and Remote Sensing Symposium, 21-25 July 2003, Toulouse, France, Institute of Electrical and Electronics Engineers, New York.

Duro J., Inglada, J., Closa, J., Adam, N. and Arnaud, A. (2003) High resolution differential interferometry using time series of ERS and ENVISAT SAR data, in Proceedings FRINGE 2003, 1-5 December 2003, Frascati, Italy, European Space Agency, Frascati. 